\title{
UMA VIDA QUE SE NARRA
}

\author{
JOAQUIM NABUCO: OS SALÕES E AS RUAS
}

de Angela Alonso. São Paulo: Companhia das Letras, 2007.

\section{K. DAVID JACKSON}

Joaquim Nabuco (1849-1910) já foi assunto de numerosas biografias.As principais foram escritas por sua filha Carolina (Vida de Joaquim Nabuco, por sua filha Carolina Nabuco. São Paulo: Companhia Editora Nacional, 1928) e por Luiz Viana Filho (A vida de Joaquim Nabuco. São Paulo: Martins, 1973). Em todas, a sua vida e personalidade são apresentadas por meio de fases e identidades bem distintas - "o abolicionista", "o Católico", "o exilado", "o jornalista", "o diplomata”-, que parecem corresponder a pessoas diferentes, unidas em Nabuco apenas pelo fio biográfico e por uma personalidade elegante, nobre e comunicativa. Ainda em outras biografias, a divisão da vida de Nabuco entre profissões e interesses variados é comum - "o parlamentar", "o escritor", "o pan-americano", "o monarquista”, "o geógrafo”, "o poeta e moralista", até "o menino de engenho". Parece um panorama de personagens de ficção, dignos dos romances de Machado de Assis, que, segundo um seu narrador, "guinam à direita e à esquerda" contraditoriamente. Além da divisão por interesses profissionais, as várias biografias de Nabuco tradicionalmente são de difícil leitura. Contêm uma ampla e densa transcrição de documentos deépoca, acompanhadas de uma série de citações encontradas na obra do biografado, fundadas na certeza de uma íntima conexão entre vida e obra. Mas com uma vida tão dispersa e variada, enraizada geograficamente em duas regiões do Brasil, no continente europeu, em Londres, depois na América do Norte, dividida por fases bem marcadas, não seria o caso de perguntar quantas vidas teria vivido Joaquim Nabuco e quantas biografias poderia sustentar?

Em Joaquim Nabuco: os salões e as ruas, da série de perfis brasileiros editada pela Companhia das Letras, Angela Alonso, socióloga da USP, prova que a biografia de Nabuco ainda serve para contar uma história fascinante, escrita numa prosa acessível, com um vivo retrato das transformações sociopolíticas havidas entre 1860 e 1910 servin- 
do de pano de fundo. Nesta nova biografia, a socióloga, consciente dos profundos laços entre literatura e sociedade, inverte o quadro e começa não pelas vidas de Nabuco, mas por suas "três mortes", em cidades diferentes. Com esse toque, reminiscência de realismo mágico, já põe em primeiro plano o perfil de um Nabuco muito parecido a um personagem de ficção. Ao começar pelo fim, acompanhando as três mortes, a biografia faz dele, como dizia Jorge Amado do seu antiherói Quincas Berro D’Água, um campeão da morte: a primeira em Washington, D.C., onde o embaixador foi velado pelos altos oficiais do governo norte-americano; a segunda, quando desembarcou no Rio de Janeiro alguns meses depois como intelectual monarquista, recebido por "senhores circunspectos, de cartola e casaca"; e finalmente no Recife, onde o abolicionista e filho pródigo passou pelas alamedas entre normalistas de branco, escoltado por ex-escravos. Ao começar pelas últimas homenagens, possível alusão às primeiras páginas do romance de Brás Cubas, Alonso põeem relevo a narrativa retrospectiva a seguir, apresentada no estilo de um diário quase íntimo, composto de pequenas observações pertinentes, com traços de Bildungsroman e de drama histórico. Os seis capítulos, ou atos, em que a biógrafa divide a vida de Nabuco ("Dândi", "Asombra do pai", "Aexperiência inglesa", "No olho do furacão", "Ostracismo e memória" e "Dom Nabuco") são apresentados não como momentos soltos ou determinantes, como em biografias anteriores, mas como ensaios em que os estágios de sua vida são caracterizados por três grandes linhas de interpretação: pela sedução da figura, pela transitoriedade geográfica e por uma obstinada e fadada incompatibilidade entre desejos e obrigações.

Nas mudanças de fase, há momentos de crise, de transformação e remodelação: Nabuco, quando volta correndo ao Brasil com a notícia da morte do pai, muda de nome, deixando o apelido do jovem dândi, "Quimquim", para se tornar simplesmente Joaquim Nabuco, assumindo o nome da família na política nacional. Quimquim dominara por 29 anos um esteticismo requintado, muito de época, que o levou cedo aos Estados Unidos e à Europa, facilitou os namoros e motivou a opção pela diplomacia, ao mesmo tempo em que o deixava insatisfeito com as intrigas da vida política. Na primeira estada nos Estados Unidos, flertou com as "misses" da alta sociedade de Nova York, ocasião em que ficou seriamente cativado pelas musas Minnie Stevens e Fanny Work. Quando jovem, esse parece ter sido o seu papel preferido, mas até os quarenta anos sua liberalidade foi circunscrita pela paixão por Eufrásia Teixeira Leite, herdeira de uma vasta fortuna da aristocracia cafeeira conservadora do Vale da Parába, cuja família jamais poderia aceitar o filho do liberal Nabuco de Araújo, a quem ela manteve fidelidade até a morte. A biografia expõe esses contornos da vida, da personalidade e da fortuna. 
A autora logra disfarçar o trabalho de pesquisadora, dos anos de consulta minuciosa e do vasto número de fontes citadas, numa prosa simples e direta. As suas fontes são principalmente a correspondência ativa e passiva de $\mathrm{Nabuco}$, mais os comentários avulsos sobre ele encontrados em livros de companheiros de geração, ou em artigos ou biografias sobreeles. Citando trechos de correspondências e comentários de terceiros, Alonso segue Nabuco cronologicamente pelos salões, ruas e navios em que andava - são tantas viagens para a Europa que pareceumverdadeiro bailado transoceânico. Aexposição precisaconstantemente resumir momentos históricos e políticos, criar contextos culturais e descrever ambientes geográficos, o que exige uma caracterização sucinta. Prepara assim o terreno para contar as peripécias de Nabuco, seja em Londres, Paris, Roma, Nova York ou no Brasil. Tenta tornar tudo atual pelo emprego da primeira pessoa ou do discurso direto livre, ao descrever até os detalhes mais esdrúxulos de estratégias e posições políticas, ou de contornos da vida particular. Por ser uma pesquisa centrada na correspondência, sobressai o retrato da pessoa. Quando faltam cartas de determinados anos, como de Eufrásia para Nabuco na década de 1880, escasseia o seguimento do tema e passa para outras esferas do multifacetado Nabuco. Não falta material, portanto, para um fino perfil do homem e do decorrer de sua vida. Alonso injeta toques sutis de ironia e humor, criando através do conjunto uma perspectiva ou julgamento implícito, que acompanham a biografia em sotto voce, lembrando-nos de um mundo de comportamentos e valores que possam parecer irreconhecíveis e estranhos. Resume o encontro entre Nabuco e Eufrásia a bordo do Chimborazo, por exemplo, com a frase, "O belo e a bela se enamoraram [...]" (p.52). O título do capítulo "Dom Nabuco" é também ilustrativo. Quando Nabuco volta a Londres como chefe de legação, os ingleses, não querendo chamá-lo de "sir" e para evitar a desconsideração que tinham pela América do Sul, resolveram considerá-lo diplomata ibérico. Daí começaram a chegar as cartas endereçadas, à maneira espanhola, a "Dom Nabuco". Apesar do engano, ou da leve malícia muito inglesa, há outra possível leitura mais machadiana, nas entrelinhas, que retrata um diplomata monarquista requintado, com o "dom" dos grandes jantares e recepções de gala. Quando Nabuco recolhe e envia para Machado de Assis o ramo do carvalho do poeta Tasso, da Itália, comenta a autora mais diretamente: "[...] o presente era um reconhecimento, raro em Nabuco, de uma superioridade" (p.336).

Essa nova biografia consegue cativar o leitor ao comunicar o drama das aspirações e das qualidades da pessoa. Mantém um estilo simples, de leitura agradável, sem cair no popular e nunca reducionista, caracterizada pela seleção do detalhe significante que impressiona e marca. Em Os salões e as ruas há muitos momentos 
saborosos, sempre com detalhes curiosos e às vezes engraçados. É isenta de longas citações da obra de Nabuco ou de documentos oficiais. Poderíamos caracterizá-la, continuando a comparação com Machado, pelo estilo do memorial do Conselheiro Aires: direto, elegante às vezes, desenvolvendo-se de maneira romanesca. Há sempre uma variedade de pequenas citações que delineiam um perfil de um indivíduo freqüentemente às voltas com as exigências do seu meio e do seu tempo. Nabuco teria se sentido mais à vontade talvez no século XVIII, monarquista que era, apreciador das damas e dos salões, mas não teria chegado à grandeza que lhe ofereceu a sua época, repleta de grandes transformações.

A concisão e legibilidade da biografia, porém, têm o seu preço. As alusões indiretas ocupam o lugar de considerações mais sérias e acadêmicas sobre a cultura do fim do Segundo Reinado e as possibilidades expressivas de Joaquim Nabuco, considerando sua formação e personalidade. Para compensar a lacuna, o texto é suplementado por um ensaio de indicações bibliográficas, completo e atualizado, que indica as fontes para encontrar qualquer obra publicada de Nabuco e comenta a bibliografia secundária mais importante até 2006 . Há ainda uma cronologia e índice onomástico. Assim o volume resgata a sua utilidade para historiadores eacadêmicos, sem sacrificar a exposição cândida e íntima.

A feição literária coloca em primeiro plano um Nabuco personagem e escritor, à procura do seu papel e consciente do significado das suas futuras biografias. Alonso compara o livro de memórias Minha formação, de 1900, a Dom Casmurro, romance de Machado de Assis do mesmo ano, na medida em que "juntava as pontas da vida" (p. 290). O casamento com Elvina Torres Soares Ribeiro, em 23 de abril de 1889, após o fracasso do longo namoro com Eufrásia, a quem Nabuco dirigira nada menos que quatro propostas de casamento, é analisado segundo o desfecho do romance machadiano Iaiá Garcia, em que "cada um seguiu o destino do seu grupo", recusando o anticonvencional. Não é a única semelhança que a autora percebe entre Nabuco e certos personagens de Machado, até alegando que "avida corre mais próxima dos enredos de Machado de Assis que dos de Alencar" (p. 244).Vêna considerável produção literária de Nabuco, sobretudo na década de 1890, época de formação da Academia Brasileira de Letras e correspondência com Machado, um impulso que lhe permitiria reinventarse, no mundo político e social, na esteira das fases sucessivas:

Pormeiodoslivros, Nabucoremodelousuabiografia. Aatraçãodo mundo do dândi o fizera adido, carreira interrompida pelo chamado de uma causa, a abolição. Cumprida a missão, viera a República. Esperara passar a turbulência da transição para repor a vida no leito natural, a diplomacia (p.291). 
Segundo a socióloga, Nabuco era um amálgama, um personagem em estados de transformação que representou a nação e superou os primeiros revezes da sorte. Voltou ao Brasil para tentar a carreira política, no caminho do pai e do avô, e encontrou os heróicos papéis de abolicionista, literato e diplomata. Achou grandeza ao servir à República, que não aprovava, e de ser porta-voz de uma nova política em Washington, D.C., cidade de que não gostava. O perfil é de um personagem guiado pelas grandes linhas da formação e da personalidade, pelo contraponto de uma forte "atração do mundo", que fez dele um viajante constante e diplomata nato, e a demorada procura por uma causa digna que fizesse jus a seus ideais e à sua nobreza de estilo. A narrativa chega ao esperado desfecho triunfal apenas nos últimos atos, quando a morte já aparecia no horizonte. Fecha a história, que começou com a viagem para o túmulo, com uma mistura de simpatia, ironia e resignação, atitude reservada para os raros casos que parecem mais improváveis do que a ficção.

K. DAVID JACKSON é professor na Universidade de Yale. 